\title{
TRANSCRIBIR EL RÍO DE LOS SUEÑOS \\ (ENTREVISTA A RAÚL ZURITA)
}

\author{
POR \\ Juan Armando Epple \\ University of Oregon
}

Raúl Zurita representa, sin duda, una de las voces más destacadas de la nueva poesía chilena. Su obra ha ido consolidando un designio creador sustentado en una poética de registros claramente definidos, que se expanden y dialogan consistentemente en una serie que incluye Purgatorio (1979), Anteparaiso (1982), Canto a su amor desaparecido (1986), El amor de Chile (1987) y un extenso poemario que estaba completando cuando tuvo lugar esta entrevista, y que acaba de publicarse: Canto de los ríos que se aman (1993). En 1988 obtuvo el premio de la Fundación Pablo Neruda, instaurado en Chile para valorar a los autores más destacados de las nuevas promociones poéticas del país. Actualmente se desempeña como agregado cultural de la embajada de Chile en Italia. Esta entrevista se realizó en junio de 1988 en Temuco, donde Raúl Zurita hacía uso de una beca anual como escritor en residencia, patrocinada por la Fundación Andes.

JAE: Aunque ya habías empezado a publicar antes de 1973 (apareces, por ejemplo, en la antología de poesía chilena editada por Martin Micharvegas en 1972), desde tu primer libro se advierte un proyecto global, unificado y consistente, situación que no es usual en la poesía chilena. ¿Como surgió esta preocupación tuya por asumir, a partir de Purgatorio, un proyecto poético de esta envergadura?

RZ: Esto tiene que ver con muchas cosas, y de hecho tiene sus raíces en el golpe militar de 1973. Yo siempre he tenido la sensación de que hemos vivido dos golpes: uno es el concreto y factual, el de septiembre del 73 , y otro, más silencioso pero quizás más demoledor, fue cuando todo este país o gran parte de él se dio cuenta de que la dictadura no sería un fenómeno corto y pasajero, sino que tenía para largo. Esta percepción comenzó a hacerse presente en el segundo año de la dictadura. Yo recuerdo el año 1975 como un año especialmente represivo a todo nivel, incluso para aquellos que estábamos fuera de la prisión. Nos dimos cuenta que eso no sería algo transitorio. Se habían roto todos los espacios públicos, todas las instancias de concertación o diálogo. Yo estaba absolutamente solo, atravesando por un período extremadamente difícil, y en un momento tuve la curiosa intuición de que la única forma posible de vida que se me ofrecía era intentar releer mi propia experiencia. O sea, hacer de todo lo que me había pasado o me estaba pasando, la base de una idea $o$ un proyecto donde yo pudiera leer nuevamente mi vida y corregir 
imaginariamente mi propia existencia. A partir de un hecho completamente atroz y absolutamente solitario, cuando me quemé la cara (me imagino que como una forma de exorcizar la tentación del suicidio), descubrí la necesidad de re-crearme y comunicarme con otros. Cualquiera que haya vivido situaciones de angustia, de soledad, de miedo, sabe que independientemente de tantas cosas hay experiencias que nunca van a acceder al lenguaje, a constituirse en palabras. Que nunca van a poder contarse. Pero entendí también que esa situación tan depresiva, que estaba más allá de cualquier posibilidad enunciativa, era capaz de expresar algo. Esa quemada en la cara podía leerse entonces no como un gesto de autoanulación, sino como el primer chillido de la guagua. Pensé que ese era el inicio de un itinerario que debería concluir con el vislumbre de la posibilidad de ser feliz. Y en eso he estado estos últimos $13 \delta 14$ años. A partir de allí he venido entendiendo la poesía como la corrección y la re-invención de la propia experiencia. De hacer de nuestra vida algo parecido a las lecturas míticas. Y de adueñarnos, en ese sentido, no sólo de nuestra experiencia, sino de toda la historia. Yo he sido un lector bastante asiduo de la Biblia, desde el Génesis ...

JAE: En tu poesía se detectan justamente dos grandes bases: una de tipo religioso, que es la Biblia, y otra de tipo laico, que es la Divina Comedia.

RZ: Si, yo he pensado que la Biblia, más que ser un relato fabuloso o sagrado, desde el comienzo hasta el final, desde el Génesis hasta el Apocalipsis, es realmente el relato de una simple vida humana. Es decir, cada uno de nosotros ha tenido su Paraíso, ha enfrentado su Mar Rojo, ha cruzado el Desierto, ha llegado a la Tierra Prometida, la ha perdido y la ha vuelto a buscar. Pienso que ese libro es tan impresionante y ha calado tan hondo en la memoria colectiva no tanto porque condense una cosmovisión religiosa, sino porque en él están descritas, formuladas, todas las vicisitudes de la vida humana.

JAE: ... ves la Biblia como una summa arquetípica de la experiencia de la humanidad.

RZ: Sí, se puede leer de esa manera.

JAE: ¿Y cómo se inserta en tu obra la Divina Comedia?

RZ: Ese libro es parte de mi experiencia personal de formación, y lo rescato además como un homenaje. Mi abuela, que era italiana, me contaba cuando niño escenas de la Divina Comedia, sobre todo del Inferno. Conviví con esos relatos desde la infancia. Después me he ido dando cuenta que toda la fascinación que he tenido por ese libro no es de tipo intelectual, sino que es una relación emotiva. Cada vez que me doy cuenta que he apelado a ese libro es porque vuelvo a nombrar a mi abuela. Y aún más: es como dejarla a ella que hable. De allí que ese texto sea para mí una estructura básica, porque es el primero que "viví".

JAE: Tu poesía está de alguna manera vinculada a estos modelos o fundamentos de lectura, y la crítica va a tener que hacerse cargo de ello al analizar tu obra.

RZ: Sí, yo creo que es una base doble. Sin embargo, también creo que no toda la realidad está contenida en el lenguaje o pueda referirse a tradiciones ya formuladas lingüísticamente. El hecho de que el lenguaje, las cosas que hablamos, marquen el límite de nuestra posibilidad enunciativa, y de nuestra posibilidad de pensamiento, no significa que no haya cosas que estén del otro lado, y creo que ésa es la base de 
la experiencia estética. Cuando una persona va a un concierto, y siente que algo lo agarra del pelo y lo remece, despertándole todas las fibras emocionales, puede vislumbrar que la obra de arte, en su estado máximo, es el modo más patético de nombrar dentro de su lenguaje aquello que sin embargo ya no le pertenece. Por eso es emocionante y es patético. Tú no puedes decir lo que está fuera del lenguaje, porque lo dirías con palabras, limitando esa percepción. Toda obra de arte, toda poesía, incluso en sus expresiones más arcaicas, de repente en sus momentos más extremos, pareciera querer decirnos con el lenguaje de este mundo aquello que ya no pertenece a este mundo. Por ejemplo el final del Edipo en Colono, una obra que me ha impresionado tanto: al final Edipo muere, después de haber pasado por tantas pruebas, "pero había en su rostro una expresión de tal paz y dulzura que ningún mortal podría describirlo". Creo que allí hay un ejemplo del centro más gravitante de lo que es la odisea poética. El autor, enfrentado a esa imagen tan profunda, lo único que puede decir es que nadie será capaz de describirla. Entonces yo pienso en un paraíso probable. Creo que la experiencia humana, de tanto en tanto, se encarga de traerlo a colación. Hay una situación que otras veces he citado: cuando un hombre está frente a una mujer, y de repente siente que todo lo que pueda decir, "te amo", "te quiero", "te adoro", está demás. Porque todo lo que quiera decir apela a un sistema de comunicación muy precario, que no alcanza a definir la raíz profunda de su realidad. El lenguaje, que es lo único que tenemos, en ciertas ocasiones se revela sólo como la historia de un largo malentendido, de una especie de condena a la incompletud o la infelicidad. Cuando oigo decir que la gran misión de la poesía es la palabra, rescatar las palabras, pienso en realidad que es una afirmación que se hace con el pecho bajo. Que en realidad no es eso, sino el esfuerzo de transcribir esos grandes sueños y esas grandes pesadillas que gesta una comunidad o una colectividad, y que siempre tienen relación con aquellas cosas que finalmente más le importan: el deseo de ser felices. Y que esa felicidad se perpetúe. Hay, por así decirlo, un horizonte soñado, in-narrable, in-descriptible, al que pienso que apunta finalmente toda literatura, pero también excede a las posibilidades de la lengua. Eso es lo que podríamos llamar "el paraíso de toda literatura posible". Tal como aquello que no se puede decir, que no se alcanza a sacar más que con un nudo en la garganta, es lo que podríamos llamar "el infierno de toda literatura". Y a nosotros nos toca transitar, siguiendo la metáfora, por esta especie de "purgatorio" de las palabras, el purgatorio del lenguaje. Ésa es nuestra experiencia. Es aquí donde adquiere sentido, para mí, el símil con la Divina Comedia. No es la traducción literal, sino cómo lo podemos transferir a nuestra situación de seres que tratamos de comunicarnos, que tratamos de que alguna vez el alma se nos asome un poco por los ojos para decirnos algunas cosas. La poesía es la tensión que nos toca vivir en esta experiencia de decir palabras sin saber nunca cuánto podemos decir.

JAE: ¿Cómo ves tú la relación entre esta búsqueda de una plenitud de la comunicación, que buscaría alcanzar una especie de ámbito paradisíaco, con la noción de utopía? La utopía es también un sueño de igualdad plena, pero un sueño que está más allá de nuestras posibilidades sociales. 
RZ: Es verdad, son dos concepciones estrechamente ligadas, salvo que la utopía implica, en el fondo, el "lugar de ninguna parte". En ese sentido tiene valor histórico sólo como testimonio de un presente, no como futuro virtual al que se pueda acceder. En realidad, a través de distintas utopías, sociedades enteras han hablado de sí mismas, informando sobre sus sueños y sobre los dilemas de su presente. Ahora, yo sinceramente creo, y lo creo de verdad, que se avanza hacia un mundo radicalmente distinto. Que lo más probable es que nosotros, y nuestros hijos y nietos, no lo alcancemos a ver, pero que algún día será realidad. Yo creo que todo este tremendo avance tecnológico, que por el momento es otro instrumento más de dominación, en un día no lejano será realmente patrimonio de todos. ¿Y qué significa este avance? Yo quiero ver, y trato de ver, que todas estas innovaciones tecnológicas no son sino la puesta en escena de una especie de tiempo curvo, en el cual al final todas esas visiones arcaicas que nos precedieron, que significaban una relación sagrada, vivencial y emocional con todas las cosas del universo, a través de la técnica vuelven a reencontrarse. Yo creo que toda esta verdadera pasión por las búsquedas astronómicas, por el estudio del firmamento y de las galaxias, no es sino para volver finalmente a establecer esa relación sagrada y mágica que los pueblos tenían antes con el universo que habitaban. Yo creo que en ese sentido se está avanzando hacia un reencuentro con las relaciones más arcaicas y primitivas que teníamos con el universo, y por eso para mí este desarrollo tecnológico tiene a pesar de todo un sentido positivo. La utopía narra algo imposible. Pero creo que en realidad estamos frente a mundos posibles. A mí me impresiona mucho el hecho de que se hallan inventado todos estos sistemas globales de comunicación, porque en última instancia está el intento por volver a establecer el tipo de relaciones que se tenían en las sociedades pre-escriturales, por llamarlas así. Recuerdo que después del 11 de septiembre del 73, mientras estaba en la bodega de un barco, yo sentí de pronto que todos aquellos seres que estaban allí en ese momento eran mis amigos, sentía que la nitidez del pensamiento en ellos era tan fuerte porque no había ninguna posibilidad de comunicación, que los medios técnicos (el teléfono, el télex) resultaban pequeñas parodias de esa comunicación infinitamente más intensa que se puede lograr entre distintos seres humanos, y que probablemente es la que prevalecía en otros estadios anteriores de la civilización, que hemos olvidado o perdido. Entonces, cuando hablo de una plenitud por la que se estaría jugando la poesía, por así decirlo, lo pienso no como un simple sueño poético, sino como una posibilidad histórica.

JAE: Si bien lo entiendo, se trataría de restituir al lenguaje de hoy ciertas funciones de comunicación que se perdieron, $\mathrm{o}$ de hacer que esas viejas funciones se rearticulen a las nuevas necesidades expresivas ...

RZ: Sí, yo creo que nuestra lengua es el patético recuerdo de un estado de comunicación sagrada, mágica, vivencial y emotiva con todos los elementos de la realidad. O sea, el lenguaje que nosotros hablamos ya es ese recuerdo también; y a la vez atrae las condiciones en las cuales se impuso. Nosotros hablamos una lengua, el castellano, que hace quinientos años se impuso a sangre y fuego sobre este continente. $\mathrm{Y}$ cada vez que hablamos, de una u otra forma traemos el recuerdo de 
esa especie de gran cataclismo que significó la conquista. El castellano que nosotros hablamos no es el mismo castellano peninsular; el nuestro está cargado de una historia diferente, que incluye todo lo que sepultó o condenó a la marginalidad. En este sentido, el poema de Neruda "Alturas de Macchu Picchu" marca un hito impresionante. Lo que allí se lee es finalmente la reconciliación de los hablantes con la lengua que hablan, la posibilidad de que esa historia pueda ser algún día ganada colectivamente. El poema implica en ese sentido una especie de futuro de la lengua, cuando ella se reconcilie finalmente con todo aquello que marginó, y por lo tanto quienes la hablan se reconcilien no solamente con su experiencia sino también con la experiencia del pasado colectivo. Desde la primera escena que recuerda nuestro continente, cuando un fraile le pasa la Biblia a Atahualpa, diciéndole que es la palabra de Dios, y éste la tira al suelo porque no oye salir esas palabras del libro, justificando ante los conquistadores una legalidad represiva, nosotros hablamos un idioma que carga con las huellas de las condiciones en que se impuso y con sus gestos alternativos. Al mismo tiempo, como en todo lenguaje, lo veo como la reconstrucción, también patética, de un estado de armonía o de relaciones sagradas con las cosas.

JAE: Esta propuesta pasa, primero, por el derecho y la capacidad de comunicación de distintos grupos que están coexistiendo en un mismo espacio social ...

RZ: Correcto.

JAE: ... y segundo, pasa por la revaloración de ese espacio heterogéneo como habitat de adhesión natural y organizado de acuerdo a parámetros solidarios de convivencia social y cultural.

RZ: Por supuesto.

JAE: Tengo la impresión de que en tu poesía comenzaste por una revaloración del espacio natural como un fundamento para propiciar la rearticulación de estos (nuevos) vínculos humanos. Desde el desierto de Atacama, en tu primer libro, hasta el que estás escribiendo ahora, Canto de los ríos que se aman, la naturaleza es aprehendida como un mapa elemental desde el que se edifica, como en un nuevo comienzo, una propuesta de vida que ya se había realizado en forma precaria, malbaratada $o$ traicionada.

RZ: Si uno lee La Araucana, y esto puede parecer pedante decirlo, uno se da cuenta que el paisaje es algo que llega con los conquistadores. Antes de la llegada de los conquistadores había otra cosa, distinta a lo que hoy entendemos por paisaje. En Ercilla los paisajes son inicialmente escenarios tópicos de la acción épica o de motivos clásicos del canon europeo. Y en la medida en que avanza la gesta se van constituyendo distintivamente en paisajes. Creo que en realidad los paisajes que miramos no son sino grandes escenarios que nosotros vamos llenando con la pasión de vivir. Es esa pasión la que levanta las montañas, las llanuras o los ríos que miramos, produciendo un vínculo misterioso con ese panorama objetivo. Si dos personas miran y reconocen una montaña, por ejemplo, y uno de ellos no tiene vínculo alguno con la civilización, la cultura o la lengua en que está inserta, ambos van a ver cosas completamente distintas. Para uno será una forma del paisaje, para otro podrá ser una representación sagrada del mundo. $\mathrm{Y}$ es porque cuando uno 
habla y nombra no es sólo el individuo el que habla, sino todos aquéllos que lo han precedido. La montaña es la suma de las miradas que ya la han visto. Cuando yo hablo no soy solamente yo el que hablo, sino que en realidad son todos aquéllos que me han precedido, y que de alguna manera vuelven a vivir cada vez que yo miro y nombro algo. Entonces, cada experiencia de percibir y hablar es la puesta en evidencia de las infinitas miradas y los infinitos cuerpos que han visto antes que yo y que han hablado antes que yo, y a quienes con cada una de nuestras palabras y nuestros gestos les damos la oportunidad de una nueva vida: de volver a decir. Entonces, ¿por qué yo no coincidiría nunca con la visión de un australiano, por ejemplo? Porque él estaría cargando a la vez con su propia carga histórica de miradas, y esa suma es distinta a la suma de las nuestras. Como decía hace poco en otra entrevista, hay mucha retórica sobre el asunto de las relaciones entre las lenguas, las relaciones espaciales, etc. Pero pensando en un terreno que no me es concreto, en una región como ésta, asiento del mundo mapuche, si a la lengua mapuche no se le da un reconocimiento oficial, al mismo nivel que el castellano, desde la educación hasta la impresión de los documentos públicos, todo lo demás es retórico respecto a lo que dice hacer la nación chilena por el pueblo mapuche. Tiene que partir reconociéndose la dignidad de la lengua, de la cultura y de la cosmovisión social y religiosa del pueblo mapuche si se lo quiere considerar como parte del país. Por el contrario, vemos que todo avanza en dirección absolutamente opuesta. Pero mientras haya gente que pueda decir algo en defensa del derecho a la expresión cultural, habría que reafirmar estos principios. Sobre todo en esta región, donde de hecho existen dos idiomas, uno de los cuales sigue siendo sojuzgado por el otro.

JAE: Cuando tú hablas de la labor expresiva del poeta como voz que canaliza y reformula experiencias que vienen del pasado colectivo, esto vuelve a poner sobre el tapete el debatido tema del rango social que se le asigna a veces al poeta. El poeta aparece nuevamente con esta voluntad fundadora que nadie le ha exigido pero que se siente impelido a asumir. Y eso lo lleva a asumir también responsabilidades sociales en la vida contingente, a participar en el foro social. Es lo que ha ocurrido contigo estos años. ¿Cómo enfrentas tú esta tarea adicional?

RZ: Yo creo que los poetas y los artistas en general, por más delirante, genial o lejano que sea su vuelo, nunca van a ir más allá de lo que su comunidad o su pueblo hayan imaginado o vislumbrado en un momento. En este sentido yo creo que los poetas, los artistas, son transcriptores de sentimientos o ideas que lo preceden con mucho, y de los cuales ni siquiera son dueños. Ellos solamente transcriben sueños, pesadillas o imágenes que están en lo más profundo de las comunidades a las cuales pertenecen. Y esa es la función que cumplen. Ni más ni menos. No creo que el poeta invente nada, sino que sólo recoge. Y recoge muchas veces a pesar de él, sin saberlo, sin tener conciencia. Ése es el papel que cumple: transcribe lo que su comunidad ha padecido o sonado. Ahora, esto de verse de pronto involucrado en tantos recitales y actos públicos, lo veo y lo acepto como un deber. Yo creo que más allá de toda declaración retórica, efectivamente hay necesidad de poesía. Sobretodo en estas circunstancias de profunda depresión en que estamos viviendo en Chile, la poesía representa una especie de hálito. No digo que tengamos que construir una poesía 
ad hoc ni mucho menos, pero lo que está manifestando esta expresividad poética, y no me refiero a la mía sino a toda la que está surgiendo en estos momentos, es que este pueblo y todos los pueblos, a pesar de todas las cosas que le puedan tocar históricamente, mantienen casi incólume su reserva y su capital de sueños. Por eso sigue existiendo la poesía y el arte. Si un pueblo se quedara sin sueños entonces ya no tendría futuro. Yo creo que es por eso que en los actos políticos se sigue invitando a los poetas a que lean sus trabajos, porque hay una necesidad de ratificar que efectivamente seguimos soñando. Y eso, como te digo, no conlleva necesariamente una posición triunfalista. Yo no estoy propiciando una poesía de corte victorioso ni mucho menos, sino solamente afirmar que estamos vivos porque todavía soñamos y porque seguimos teniendo pesadillas. Yo creo que de allí viene la necesidad, más que leerla en libros, de escuchar poesía.

JAE: Me contabas que uno de los trabajos que realizaste como recopilación de material poético fue entrevistar a pobladores involucrados en las tomas de terrenos en poblaciones marginales de Santiago, quienes te contaron sus sueños.

RZ: Sí, ese trabajo está hecho, y de allí salieron diez sueños que constiyen el comienzo de un libro que no he publicado, y que se titula La vida nueva. Son diez sueños de pobladores del campamento "Silva Henríquez". Ese trabajo me costó mucho. Grabé cerca de veinte, y finalmente transcribí diez. Me costó mucho contactarme con ellos, y usar la grabadora, porque tenía la sensación de estar irrumpiendo, como forastero, en una realidad que para ellos es toda su vida. Es como una irrupción irrespetuosa en un mundo cuyas claves uno apenas alcanza a comprender. Le contaba al poeta Elicura Chihuailaf que ese fue mi primer contacto con la realidad mapuche. La gente me empezó a contar sus sueños nocturnos, aceptando esto como un chiste. Y me di cuenta que los sueños que más recordaban incluían imágenes de grandes pastizales y pájaros, que contrastaban radicalmente con el ambiente de hacinamiento en que vivían. Detrás de esto estaba el fenómeno de la emigración del campo a la ciudad. Porque aunque sean de la segunda o tercera generación de inmigrantes, persisten en ellos imágenes de la experiencia de sus padres o abuelos. De hecho habían dos o tres sueños, que tengo transcritos, con imágenes de bosques y tierras absolutamente nítidos y de gran concreción. Allí me di cuenta que esos sueños, y esto fue para mí una gran revelación, eran muy distintos a los que uno usalmente suele escuchar. Y eran distintos porque también los sueños tienen un carácter de clase. A mí me resultaron sorprendentes tanto por su belleza como porque no tenían nada que ver con las posibilidades de mi imaginación. Eran simplemente distintos. Ser poeta es hacer, antes que ponerse a escribir, un acopio o una declaración de buenas intenciones (yo voy a ser pluralista, tolerante, etc.), para que luego la vida se vaya encargando de demostrarte o desmentirte esas intenciones. Yo creo ser, tanto intelectual como emotivamente, un tipo siempre dispuesto a entender, y no a pretender entender lo que no puedo. Esta zona más oscura y marginal de la historia del país me era desconocida, pero en esos sueños se me empezó hacer patente en forma muy vivencial que efectivamente había un mundo que se había impuesto sobre el otro, y lo había sepultado en la forma quizás más terrible, que era sin matarlo del todo. Era un aplastamiento agónico, y esos 
sueños manifestaban el deseo de supervivencia. De allí pasé a darme cuenta que esa situación no era algo particularizado o lateral, sino que era una realidad que atravesaba de sur a norte todo este país. Y, después de conocer otros países, encontré que esta realidad se daba con mayor evidencia en otras regiones de Latinoamérica. En el fondo de cada uno de nosotros hay alguien a quien se le ha impedido hablar, y no obstante, todo ese impedimento está pugnando por hacerse presente, por convertirse en palabras. Por eso es que vivimos tan desgarrados. Situaciones como éstas fueron las que llevaron al suicidio de Arguedas ...

JAE: O a Violeta Parra ...

RZ: Exacto. Y ésa es para mí es una imagen crucial de lo que vivimos en nuestros países. Yo soy de Santiago, de clase media pobre, y algunas de estas situaciones sólo las he ido conociendo tangencialmente. Pero el hecho de la discriminación me define una personalidad también. En un país racista tú puedes no ser negro, pero el racismo en sí es algo que se va a manifestar de todos modos y te va a afectar aunque tú no seas una víctima directa de esa actitud. Para mí esos sueños que encontré fueron el punto que ha ido desencadenando todo lo que he ido sintiendo después ...

JAE: La poesía, entonces además de asumirla como profesión, la asumes como una ética

RZ: Creo que hay algo que diferencia a la poesía de la política. Es una diferencia amigable, pero importante. En política es necesario, y hasta es bueno, el conciliábulo, el compromiso, la concesión, en función de lo posible. Pero creo que el arte, y la poesía en particular, es un ejercicio de los extremos: están permanentemente oponiendo, frente a lo que es, lo que debería ser. Nosotros podemos ser muy conciliadores en política, pero esa conciliación no es posible en el arte. Esto lo dijo Vargas Llosa, en un sentido que yo no comparto, pero lo expresó bien: dijo que el arte era el terreno de los extremismos, pero no la política. Yo no estoy para nada de acuerdo con las últimas actuaciones políticas de Vargas Llosa, pero creo que en lo que dijo hay algo de verdad.

Hay en la poesía una posición ética, que va más allá de todas las contradicciones que puedas tener como persona. Creo que toda poesía significa o representa lo mejor que los hombres puedan dar de sí mismos. El arte en general, y la poesía, es toda la historia de los gestos más humanos, profundos y amorosos que se han dado los hombres sobre la tierra. Es por eso que después de La Pietà, de los frescos de Miguel Ángel, del Canto general, la barbarie es más bárbara y la violencia es más violenta, no porque esas obras denuncien la maldad o la violencia, sino que porque frente al amor de esas obras el horno crematorio o la sala de tortura es más atroz todavía, porque se ponen en evidencia frente a otra historia posible. Entonces, una obra de arte nunca está en el pasado, sino que está proyectándose en el futuro. Cuando uno ve el Juicio Final, de Miguel Ángel, no está frente a algo que se haya pintado quinientos años atrás, sino algo que se te pone delante en el acto de mirarlo. $\mathrm{O}$ cuando tú lees a Homero, no es una historia que se haya transcrito hace tres mil años, sino algo que está ocurriendo ahora frente a tus ojos. Siempre el arte va a ser, en ese sentido, una de las dimensiones de nuestro porvenir, de nuestro futuro. 
Nunca hay arte en el pasado, siempre es una parte de nuestro futuro. Por eso hay un gran compromiso ético en todo lo que signifique hacer arte. Pero no algo que venga de una declaración de principios. Entre los que se sienten estimulados a hacer poesía, pienso que hay dos tipos: uno que firma un certificado de exclusión, en el sentido de no aceptar muchas cosas, y otro que antes de escribir tiene una disposición de generosidad para comprender sin limitaciones. Y de pronto te vas dando cuenta que la vida te va llevando hacia eso que en un momento fue una disposición de ánimo solamente, y que en este oficio en realidad tienes que ser lo más comprensivo posible, y tienes que ser absolutamente tolerante y generoso.

JAE: ¿Eso lo llevas incluso al plano de la diversidad de propuestas poéticas que se puedan dar en un momento en un país, como ocurre en Chile?

RZ: Por supuesto. Ahora bien, siempre que uno hace algo, está haciendo lo que quiere y también lo que puede hacer. Yo creo que en este mismo momento se dan en Chile varias formas distintas, e incluso antagónicas, de entender la poesía. Y como tales, todas son válidas. Las luchas estéticas, si bien pudieron tener sentido hace 30 ó 40 años atrás, en situaciones políticas más tranquilas, hoy resultan un poco ridículas. Lo que yo sueño para la poesía, y no para la mía, sino que en general, es lo siguiente: creo que es difícil escribir sin pensar que se escribió ya Cien años de soledad, Pedro Páramo, en suma esa poderosa narrativa del continente, narrativa que a la vez es heredera de esa gran tradición poética fundada por Vallejo, Huidobro, Neruda. La poesía posterior perdió parte de su aliento, con excepción de dos o tres autores, entre ellos Ernesto Cardenal. Hoy día es preciso recuperar los desafios. No empequeñecerse frente a la adversidad, y sobre todo no confundir situaciones precarias con productos poéticos precarios. Mientras más precaria sea nuestra situación, nuestros impulsos y nuestras intenciones tienen que ser más amplios, más profundos y generosos. Y más fuertes. En ese sentido yo me siento muy cercano, emotivamente, no tanto a la generación a la que pertenezco, sino a la generación de Huidobro, Neruda y de Rokha. Y esto no por una presunción de sentirme al nivel de ellos, ni mucho menos, sino porque pienso que detrás de cada uno de estos poetas había una vida que estaba entendida y asumida como una pasión, y esa pasión era sólo la poesía. En tanto que hoy día los poetas, y hablo en general, están mucho más embebidos en sus contingencias. Yo creo que en Vallejo, en Huidobro, en Neruda, en de Rokha, había un impulso y una fuerza que los hacía más fuertes que las circunstancias que debían vivir. Vallejo muere prácticamente de hambre en Paris, pero muere escribiendo esos poemas de España, aparta de mí este cáliz que responden a toda una historia mayor. Al mismo tiempo que está muriéndose de hambre está creando una de las poesías más solidarias que se hayan escrito en nuestra lengua, una obra cuya magnitud prometía llegar a niveles impresionantes. Yo me siento emotivamente ligado a esa forma de entender la poesía y de entender la vida. Hoy día, por muchas circunstancias de todo tipo, nuestros poetas tienen que desempeñar múltiples oficios. Todos respetables. En el caso de Chile, uno ve que las agencias de publicidad, una de las vías de sobrevivencia que han encontrado los poetas, se han convertido en la tumba de muchos talentos. Yo jamás podría condenar a alguien que tiene que luchar por su subsistencia, pero 
pienso que éste es un oficio en el cual el creador enfrenta grandes riesgos, grandes dolores, y la única posibilidad de emprenderlo es tener conciencia de que es así, y desear que deje de ser así. Es un oficio duro, en el que lo vas a pasar bastante mal. Pero si persistes en tu pasión, probablemente algún día el mundo se te va a ordenar un poco a la larga. Me recuerda un poco a los profetas hebreos, cuando Dios se les aparece en sueños y les dice que tienen que comunicar su voz. Los tipos lloran, dicen que no pueden, que no son capaces, tratan de buscar todas las disculpas del caso. Eso lo veo como una situación análoga a la de quienes quieren ser hoy día artistas. Es un oficio de coraje.

JAE: Más que un oficio, tú lo ves como un proyecto vital ...

RZ: Creo que no se lo puede ver de otra manera.

JAE: En relación al libro en que estás trabajando ahora, Canto de los ríos que se aman, ¿cuál es la perspectiva de esta obra?

RZ: Es un proyecto que comencé en 1986. Inicialmente iba a ser un poema de amor. Pero fue creciendo ... La idea es la siguiente: son todos estos ríos, que van desde el Itata hasta el Backer, cientos de ríos que vienen bajando de la cordillera y de pronto inician una especie de vuelta, cambian su curso y comienzan a marchar para arriba. Suben hacia el cielo y allá dibujan todas las escenas que se produjeron en la tierra. Es un libro de unas doscientas páginas donde están narrados todos los hechos que han sucedido en esta zona. Estos ríos aparecen como el transfondo y los testigos de esta historia. Después, hablando con mi amigo Leonel Lienlaf, me contó algo que curiosamente yo presentía: me di cuenta que esta visión de los ríos del cielo es algo que participa de la cosmovisión mapuche. El me habló del huilcaleufu, "el mar de arriba", "las aguas de arriba". El huilcaleufu es el río de las pintas blancas, la vía láctea. Esto me impresionó mucho, porque fue como constatar que cuando uno bucea en sí mismo, sin haberse documentado necesariamente, encuentra esas grandes imágenes que estaban sepultadas pero que nos han acompañado siempre. Para mí fue muy impresionante, y emocionante, darme cuenta que esa imagen de los ríos en el cielo correspondía a una visión que era muy natural en varias cosmovisiones de mundo. Ahora, es difícil caracterizar algo que uno está en proceso de escribir. En este libro hay dos planos: uno es la historia, bastante real, de un gran incendio que hubo en la zona de Palena, en los años cuarenta, y que obligó a todos los moradores a bajar al valle. Esta es la historia de cinco familias que bajan y pueblan las riberas del Correntoso, el Yelcho, el Futaleufú y el Michimahuida. El poema se inicia con esta bajada, y en su configuración acudo al tópico del génesis y el éxodo.

El otro plano, o momento configurador, es la historia que se vive a partir del golpe militar, con una serie de tragedias, luchas y esperanzas anónimas que quedan sin embargo impresas en la memoria subterránea de los ríos.

JAE: ¿Como cuáles, por ejemplo?

RZ: Historias como ésta: en un lugar del sur los pobladores deben abandonar sus casas ante el temor a la represión. Al principio parecía que no iba a pasar nada, pero pronto empiezan a irrumpir las patrulleras por los ríos. Lo primero que hacen los milicos es apresar a un niño, y les preguntan por sus padres. Se trataba de una de 
esas agrupaciones de campesinos. Este niño se niega a decir dónde está el papá; entonces lo amarran a la lancha con una cuerda del cuello y lo tienen toda la noche arrastrándolo por las aguas. En la mañana lo sacan, y no tienen necesidad de golperarlo ni de preguntarle nada, porque el chico les señala de inmediato dónde se ocultan sus padres con el resto de la agrupación campesina. Después este niño se suicida, se ahorca. Hay otra que es la escena de lo que sucedió en Neltume, donde se suponía que había un campamento guerrillero, que eran unos tipos que no tenían nada de guerrilleros. Todo lo que se relata en esos cuentos, porque son cuentos breves, de una página, todo lo que se relata tiene una raíz verídica, en que el mundo aparece dividido no entre víctimas y victimarios, sino que lo que existe es el miedo, son las traiciones, son las debilidades que provocan también los victimarios, los que te van a hacer víctima de esas cosas. Cuando matan a todos estos seres, porque el hijo los denunció, está también la culpa del hijo como elemento mediatizador. Entonces, lo que el odio desata son las peores cosas que el hombre tiene, en la mayoría de los casos. Los que han rodeado a esos prisioneros, le dicen a uno que muerda a otro. El prisionero primero se ríe, como si le estuvieran diciendo una broma. Lo muerde. Ahora responde, le dicen al mordido. Y a ese grupo de treinta personas los transforman en bestias: empiezan todos a morderse, hasta que uno de ellos queda con la nuez de Adán destrozada. El odio está en provocarlos a que ellos se muerdan, ¿te fijas? Y ellos no se dan cuenta que están transformándose también en fieras, dispuestas a matarse unos a otros. Es la idea del mal, en que el victimario desata en su víctima todo lo peor que puede contener como ser humano. No es una visión muy optimista, te concedo.

Pero después viene otro gran sueño: los ríos se recargan demasiado con el peso de todos estos cuerpos que han ido cayendo sobre ellos, y empiezan su vuelta hacia las montañas, empiezan a subir nuevamente, hasta que producen otro gran sueño: alli los personajes ven las mismas escenas, pero ya desde otra perspectiva, que atrae y articula los más caros deseos de transformación y redención colectiva. Es como el mundo relatado a través de un laberinto de ríos. Se sale de uno para entrar a otro, y así. 
